\title{
Prof. Reinhold Schmaltz and his Contribution to Equine Anatomy
}

\author{
William Pérez, ${ }^{1}$ Horst Erich Köni ${ }^{2}$ \\ ${ }^{1}$ Anatomía, Facultad de Veterinaria, Universidad de la República, Montevideo, Uruguay \\ ${ }^{2}$ Institute of Morphology, University of Veterinary Medicine Vienna (Vetmeduni), Vienna, Austria
}

Disclose and conflicts of interest: none to be declared by all authors

\begin{abstract}
Introduction: Schmaltz (1860-1945) was a Professor of Veterinary Anatomy and Rector at the University of Veterinary Medicine in Berlin and a versatile scientist who also researched and published in numerous fields. In his magnificent Atlas of Equine Anatomy, he was particularly concerned with the quality of the illustrations and the overall visual impression.

Review: This article describes Dr. Schmaltz's contributions to equine anatomy through accurate anatomical descriptions associated with high-quality illustrations. Examples of his work are being presented.

Conclusion: Schmaltz was aware of the importance of good cooperation between science and art and his atlas is a result of this fruitful symbiosis over many years, to be the highest level of the combination of scientific ambition and aesthetic-artistic expressiveness.
\end{abstract}

Keywords: Equine anatomy; Art; Atlas.

Reinhold Schmaltz (Fig. 1), was an anatomist with a great sense of art. Schmaltz (1860-1945) was a Professor of Veterinary Anatomy and Rector at the University of Veterinary Medicine in Berlin (TiHo) and a versatile scientist who also researched and published in numerous other fields. In 1888 he was the founder of the Berliner Tierärztliche Wochenschrift.

In his magnificent Atlas of Equine Anatomy (Fig. 2), he was particularly concerned with the quality of the illustrations and the overall visual impression. Thus, he carefully selected the artists who made the drawings and expressed his appreciation for them not only in the preface, but also by always mentioning their names on the title page. Striving for the greatest possible clarity, he had everything drawn on a large scale and indicated the size ratio on each panel. He also considered to what extent colors should be used. "The colored representation is absolutely the ideal. That vessels and nerves be shown in color is essential. To what extent colors can otherwise be applied must be left to consideration, in view of the very considerable cost of each part."

Printing colored illustrations was incomparably more labor-intensive and expensive at that time than it is today. But Schmaltz spared neither effort nor expense and published his atlas for the most part in color. Only occasionally, in the case of the bone and muscle drawings, were pure black-and-white prints used. He also influenced the choice of reproduction technique, opting for different techniques depending on the subjects depicted. To ensure that the finished

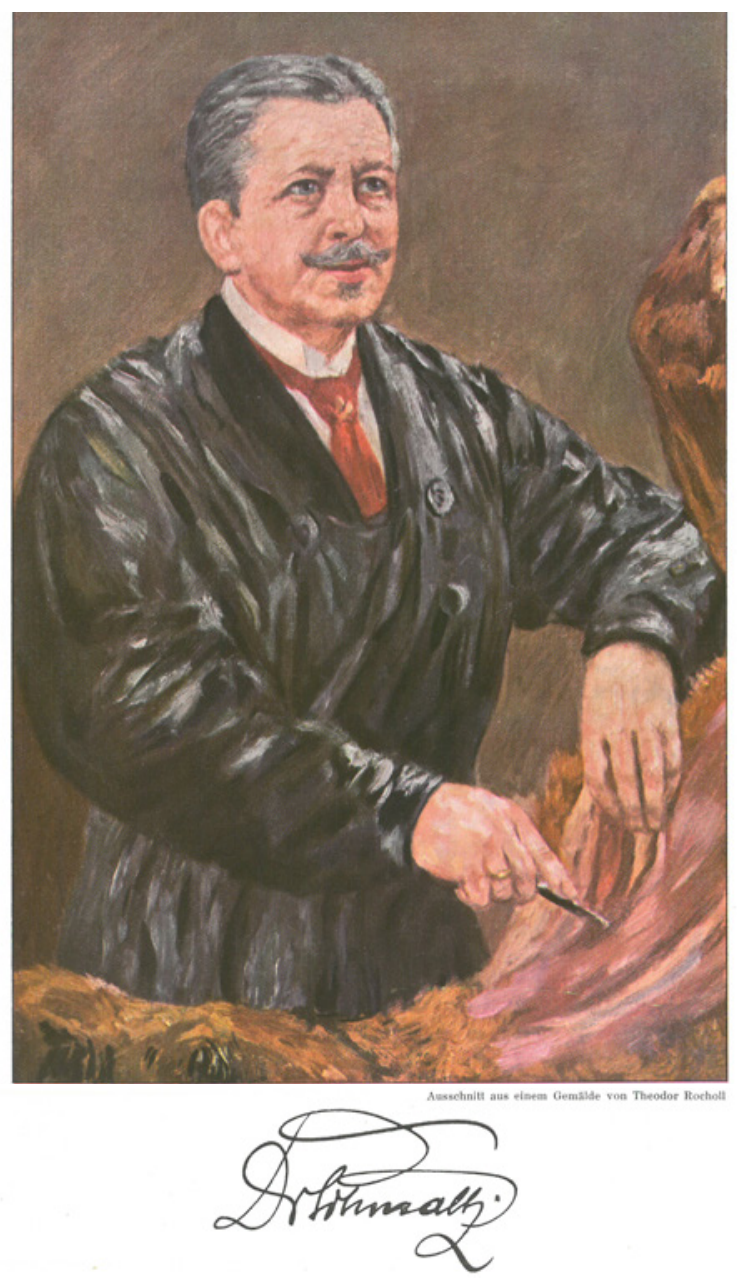

Figure 1. R. Schmaltz dissecting a horse. Painting by Theodor Rocholl, 1925. 


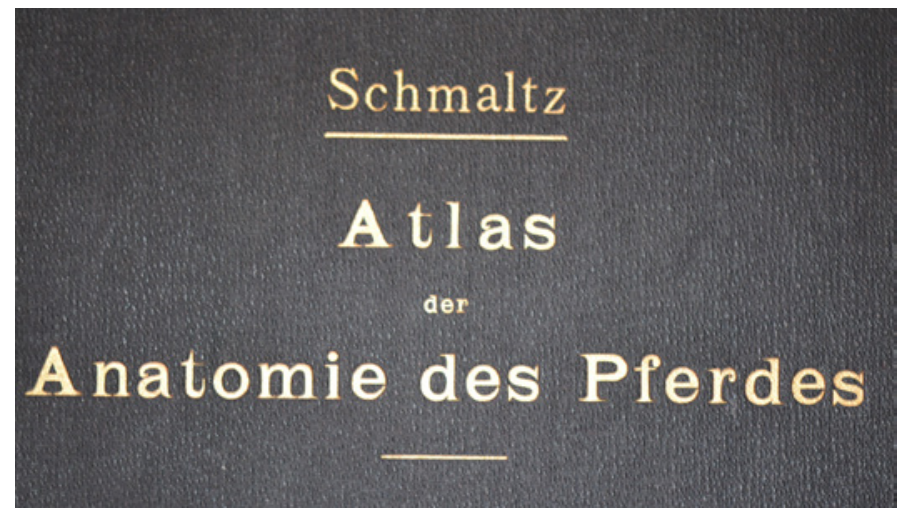

Figure 2. Cover of the Tome Topographical Myology of Schmaltz textbook.

illustrations were not marred by the necessary lettering, he made transparent cover sheets with contour lines and the designations for most of the plates (Figs. 3, 4, 5). This work appeared in five parts, whose reworkings, extensions, and new editions were also all by Schmaltz, thus retaining its individual and stylistically uniform expressiveness.

The first part contains the skeleton of the trunk and limbs and first appeared in 1900 with litographed prints. Later, in the fourth and fifth editions in 1924, autotype as a reproduction technique had developed to such an extent that Schmaltz had to have all the illustrations redrawn in order to have them printed using the new method. In this regard, he gave high praise to his illustrator, the painter Karl Hajek from Vienna, in the preface: "The artistic perfection of the drawings, since it is not my merit and, moreover, indisputable, I may well boast." Schmaltz expanded the usual representation of the bones with important additional information and detailed drawings of the joint surfaces-cartilage and angulations as well as the muscle attachment sites.

The second part deals with the Topographical Myology, first edition 1909. Three artists were involved in this: First Vincent Uwira, after his death Bruno Héroux and for additional drawings of the later new editions of 1922 again Karl Hajek. Here, too, one can hear in the preface how much enthusiastic commitment and diligence Schmaltz invested in the creation of his work. This time he chose woodcut for printing the drawings because he felt that this would best show off the muscle tissue. The xylographer was Gustav Heuer, who advised Schmaltz against having the muscles colored red, as this would not make the drawing look clearer, but less artistic. Schmaltz trusted the artist's judgment and had only blood vessels and nerves colored. And so these woodblock prints speak for themselves with their sparse coloring and, despite the density of detail, clear clarity.

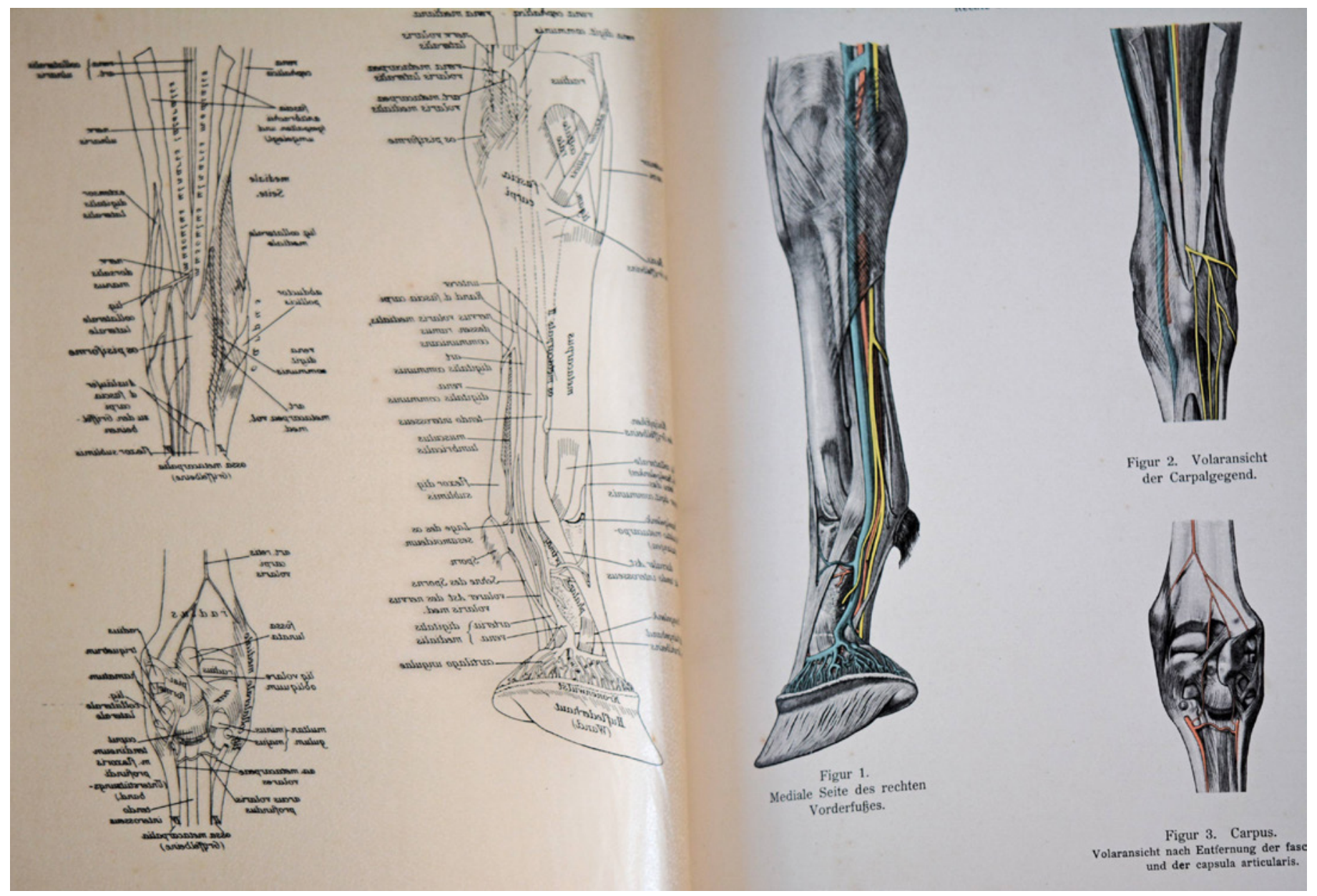

Figures 3. Some pages of the Tome Topographical Myology. 

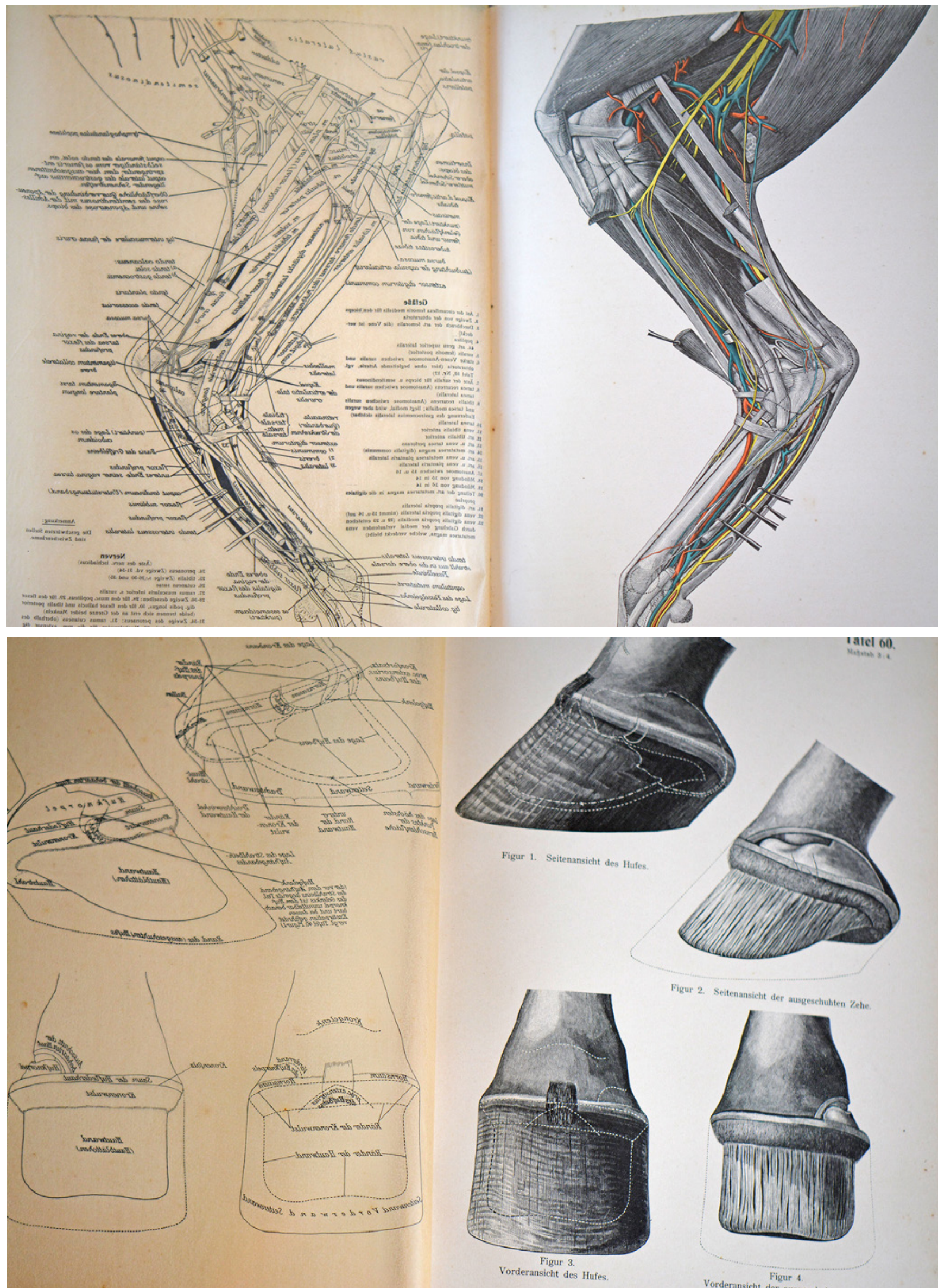

Figur 2. $\mathrm{Se}$

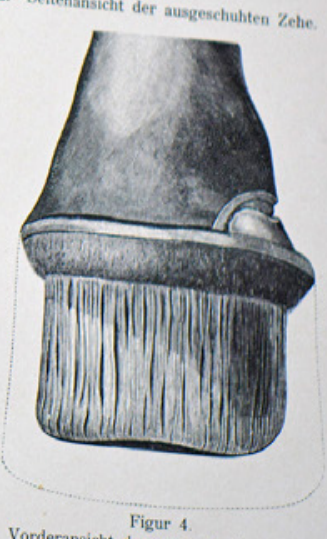

Figures 4, 5. Some pages of the Tome Topographical Myology. 
The third part appeared in 1914 and contains twelve cross-sections through the torso of a horse as well as two side views showing the position of the viscera. These were drawn from frozen preparations by Bruno Héroux, Walter Wagener and Max Rudloff. As printed as seven-color litographs, Schmaltz chose very powerful colors to enliven the images, make the details more distinguishable, and compensate for the flatness of the sectional views. However, this colorfulness, while didactically useful, distances the fourth part considerably from the others in style. The fourth part of 1927 contains the viscera in topographical and individual representations. The drawings are again in the proven quality of Karl Hajek, who succeeded with finely graded gray tones, subtle coloring and skillfully placed highlights, the various tissues and organs so real that one even seems to get an impression of their consistency and texture.

As Schmaltz also wrote in the preface about Hajek's "artistic mastery and unsurpassed technique," which "showed itself in the highest perfection especially in the depiction of the viscera and were due to his own thorough anatomical knowledge and relevantly trained eyes."
The fifth and last part, published in 1929, shows the head with all its organs and was also illustrated by Hajek. The uniquely lifelike illustrations, which are based on carefully dissected specimens, are reproduced on such a large scale that, according to Schmaltz, "they are completely capable of replacing the observation of the natural specimen," but in any case, even in the case of the complicated head situs pictures, they appear so vivid and well comprehensible that they almost seem to be "comprehensible" in the true sense of the word. The numerous representations of the middle and inner ear, which illustrate the complicated relationships of this sensory organ in an unprecedented way, are also worthy of mention. From the beginning, Schmaltz was aware of the importance of good cooperation between science and art and considered himself fortunate to have found a congenial partner in Karl Hajek, with whom he obviously also got along well on a human level, so that "working together between anatomist and artist is also conceivably easy, because there is agreement from the outset." Schmaltz himself considered his atlas, the result of this fruitful symbiosis over many years, to be the highest level of the combination of scientific ambition and aestheticartistic expressiveness.

\section{References}

Brumme M F. (1992): Lebensweg eines wilhelminischen Bürgers Biographische und anatomiegeschichtliche Untersuchungen zu Reinhold Schmaltz (1860-1945). Diss. Med. Vet. Freie Universität Berlin.
Vollmerhaus B. (2008/2009): Kleine Chronik der Veterinäranatomie im deutschen Sprachraum. 2. Aufl. Shaker Verlag Aachen.
Received: July 28, 2021

Accepted: September 20, 2021
Corresponding author

Horst Erich könig

E-mail:vetanat@gmail.com 